\title{
'Association of demographic variables versus frequency of use of core aerospace engineering e-Databases': a research survey of aerospace scientists and engineers of Bangalore
}

\author{
Ramachandran Guruprasad ${ }^{1, *}$, Payanippan Marimuthu ${ }^{2}$ \\ ${ }^{1}$ Scientist, Knowledge and Technology Management Division, CSIR-National Aerospace Laboratories, Bangalore, India \\ ${ }^{2}$ National Institute of Mental Health and Neuro Sciences, Bangalore, India
}

\section{Email address:}

gprasad@nal.res.in(R. Guruprasad),gprasad61@gmail.com(R. Guruprasad), marimuthu@nimhans.kar.nic.in(P. Marimuthu)

\section{To cite this article:}

Ramachandran Guruprasad, Payanippan Marimuthu. 'Association of Demographic Variables versus Frequency of Use of Core Aerospace Engineering e-Databases': A Research Survey of Aerospace Scientists and Engineers of Bangalore. International Journal of Science, Technology and Society. Vol. 1, No. 1, 2013, pp. 1-8. doi: 10.11648/j.ijsts.20130101.11

\begin{abstract}
Demography is the scientific study of characteristics and dynamics pertaining to the human population, including things like size, growth rate, density and distribution of a specified group. The primary reason people use demography is to create statistics--in fact, the term roughly translates to "people measurement." These allow a person to get a picture of how common specific traits within a group are. Comparing statistics over time also allows researchers to show changes that are happening in the target group. A research survey was undertaken to ascertain the 'Association of Demographic Variables versus the Frequency of Usage of Core Aerospace Engineering e-Databases' amongst the aerospace scientists and engineers of selected 16 aerospace organizations of Bangalore. The major findings of this study are: The $\chi 2$ test indicates that the demographic variable, viz., Category Wise Distribution of the Respondents, namely: Aerospace Scientist / Aerospace Engineer $(\chi 2=20.832$, P Value $=0.000)$, Occupation $(\chi 2=65.978, \mathrm{P}$ Value $=0.000)$, Qualification $(\chi 2=28.207, \mathrm{P}$ Value $=0.005)$, and Specialization $(\chi 2=42.228$, P Value $=0.003)$, by the 'Frequency of Use of Core Aerospace Engineering e-Databases' have significant association. This implies that the percentage of preference for the above mentioned demographic variables are not approximately the same [Not Uniformly distributed]. The $\chi 2$ tests for the remaining demographic variables, namely, Gender and Age-Group by the 'Frequency of Use of Core Aerospace Engineering e-Databases' have no significant association. This implies that percentages of preference for these demographic variables are approximately the same [Uniformly distributed].
\end{abstract}

Keywords: Electronic Information Resources, Core Aerospace Engineering e-Databases, Demography, Aerospace Scientists and Engineers, City of Bangalore

\section{Introduction}

As early as 1990, the usage of the Internet was extremely limited: being confined to a very small group of scientists. However, with the introduction of software for hypertext navigation and display in 1993, it became a 'worthwhile tool for scholarly work'. But then it gradually enhanced the researchers' information handling capabilities by offering them unimaginably ever growing Internet based products from hypertexts and hypermedia to the digital library and many more. In fact today, the Internet has changed the role of the traditional library services and has provided open access to the research sources/data to a wide variety of researchers and investigators almost 24 hours a day. The unprecedented growth of literature and the development of the Internet as a tool for research deserves more scholarly attention [1].

Several other studies have indicated that the Internet is one of the most important and complex technological innovations in the human history. Today, it has become arguably one of the largest and the most complete tool for information exchange ever made available to mankind. With the emergence of the Web around 1990, there has been a continuous increase in the volume of scholarly resources in the electronic format like: e-books, e-journals, e-databases, e-theses and dissertations, e-prints of research papers, and so 
on. These resources have provided a platform and scope for researchers and authors in various subject fields to stimulate their research productivity. Today, the Internet is seen as the best alternative medium to search for scholarly literature and to use web resources to support their research productivity [2]. Also, since 1990s, the internet has become the primary platform for libraries to build and deliver information resources, services, and instructions [3].

An e-Database is a file or collection of bibliographic citations or records of materials stored electronically in a manner that can be searched, retrieved and manipulated. An e-Database is an organized collection of information, of a particular subject or multi-disciplinary subject areas; information within an e-database can be searched and retrieved electronically. Contents include - journal articles, newspaper articles, book reviews and conference proceedings which are usually updated on a daily, weekly, monthly or quarterly basis. Basically, there are two types of e-databases: (a) Full-text databases and (b) Bibliographic databases. Full-text databases contain the whole content of an article such as citation information, text, illustrations, diagrams and tables. Bibliographic databases contain only citation information of an article, such as author name, journal title, publication date and page numbers.

On the other hand, an Online Database is a database accessible from a network, including from the Internet. These online databases are delivered primarily via a web browser. They are often purchased by a monthly subscription. They embed common collaboration features such as sharing, e-mail notifications, etc. Another definition says that an online database is 'an electronic collection of information, often containing journal articles, or references to journal articles, accessed via the Internet'.

Today, e-databases are key information resources within library information resources. Facing up to the consistent rising costs from the market, it is very critical for librarians and library executives to select core e-databases, based on their discipline-specific programs and subjects. Within the limit of their operating budgets, academic and research libraries should expand their e-database coverage as much possible as they can [3].

For an aerospace scientist or engineer e-databases constitute an important formal e-reference source for their day to R\&D activities and to keep in touch with global R\&D. They aspire for 24 hour access, instant access and desktop access to these electronic information resources.

\section{Review of Literature}

Nikam et al., [4], mention that, e-information resources in general and e-journals/databases in particular have made enormous impact on the scholarly communication of academia in universities and related research institutes. Consistent use of these resources by the scholarly community has not only increased research productivity but also added to the quality. E-journals have made the access of scientific information convenient and easy.
Lawrence [5], addresses the need to analyze user behaviour in particular the behaviour of aerospace engineers and scientists. The prospects for integrated data base access at the individual desk top are reviewed.

Blados and Cotter, [6], in their paper highlight that Scientific and technical information (STI) is a valuable resource that represents the results of large investments in research and development (R\&D) and the expertise of a nation. NASA and its predecessor organizations have developed and managed the pre-eminent aerospace information system. We see information and information systems changing and becoming more international in scope. They also point out that the development of aeronautics and astronautics in individual nations has also led to initiatives for national aerospace databases. Considering recent technological developments in information science and technology, it is time to reconsider the mutually beneficial possibilities offered by cooperation and international resource sharing. This paper raises for consideration of new possibilities for unifying the various aerospace database efforts towards a cooperative international aerospace database initiative that can optimize the cost/benefit equation for all participants.

O'Flaherty, J. J. [7], mentions in his paper that, Aerospace library collections are a well-defined pan-European subject, for which standardized access and interconnection can add enormously to their value over any one collection and allow libraries with less-developed library services to improve these facilities and at the same time enable those which are more advanced to upgrade their systems. EURILIA, which was part of the EC Libraries Programme aimed to enhance the Libraries' R\&D and education process which underpins the aerospace sector by establishing a new service based on researched user information needs and development of a standardized pan-European system for information access, retrieval, image browsing and document delivery.

Jeong, et al., [8], emphasizes that while developing information technology and improving engineering environment, modern aerospace technology requires even larger scale computing and data management. In order to provide a uniform aerospace development infrastructure, three perspectives are required (i.e., integration and management of aerospace resources located in multiple organizations and areas; facilitating human collaboration in aerospace fields; and remote access and operation of aerospace facilities and instruments).

Pinelli, et al., [9], in their two independent pilot studies as part of the phase-4 NASA/DoD Aerospace Knowledge Diffusion Research Project investigated the technical communications practices of Israeli and US aerospace engineers and scientists. Both studies had the same five objectives: first, to solicit the opinions of aerospace engineers and scientists regarding the importance of technical communications to their profession; second, to determine the use and production of technical communications by aerospace engineers and scientists; third, to seek their views about the appropriate content of an 
undergraduate course in technical communications: fourth, to determine aerospace engineers' and scientists' use of libraries, technical information centers, and online database; and fifth, to determine the use and importance of computer and information technology to them.

Sripada, et al., [10], in his paper points out that, the aerospace industry poses significant challenges to information management unlike any other industry. Data management challenges arising from different segments of the aerospace business are identified through illustrative scenarios. These examples and challenges could provide focus and stimulus to further research in information management.

Hatua, et al., [11], discuss a methodology that was adopted for construction of a domain-based information system, known as Aerospace Information System (AERIS), comprising six distinct steps in identifying and sourcing, evaluating and then technically integrating resources into the information system. AERIS is an integrated gateway for resources in the domain of aerospace science and technology. AERIS is designed to provide information from varied sources such as formal publications (e.g. articles), aggregators (e.g. harvesters) and also informal resources such as blogs and discussion fora. Their research work provides a model for a comprehensive integrated gateway to domain-based information using open-source tools.

Riahinia et al., [12], in their survey study have indicated that 63.4 per cent of respondents use online databases, followed by search engines (24.3 per cent), and print materials (11.3 per cent). Participants ranked Google as the most favourable search engine. In a comparison to using databases versus search engines, 58.4 per cent of respondents stated that they use online databases for seeking scientific information, while 33.6 per cent use search engines.

Sharma et al., [13], emphasize in their study that, e-journals are the most preferred e-resources in NDRI i.e. 50 (76.92 per cent) followed by WWW 41 (63.08 per cent), e-news 27 (41.54 per cent), e-mail 25(38.46 per cent), e-databases 21 (32.31 per cent) and e-books 15 (23.08 per cent).

Kamba [14, 15], in his paper highlights that today growing numbers of higher institutions in Africa are bringing ICT into their instructional and library activities. The author inter-alia refers Bonzi who found access to database and use of computers as engine of development in research and facilitators to faculty research/production and dissemination.

Bankole [16], stresses in his study that, the two University Libraries at Nigeria need to subscribe to more relevant online databases for the scientists and create awareness on availability of these resources. The awareness programme if well carried out will make the library an attractive place for the scientists to satisfy their information needs for academic and research purposes.

Maharana et al., [17], in their research survey of faculty at Sambalpur Univeresity have highlighted even though, 58
$(82.86 \%)$ respondents indicated that they use e-journals, their study also revealed that e-articles, e-thesis and dissertations and e-databases are used by more than $50 \%$ of the faculty.

\section{CSIR-National Aerospace Laboratories and its Aerospace Database Services to its Scientists and Engineers}

The National Aerospace Laboratories is India's premier civil aviation $R \& D$ aerospace research organization in the country. Its main mandate is the 'Development of aerospace technologies with strong science content and with a view on their practical application to the design and construction of flight vehicles'. NAL is also required 'to use its aerospace technology base for general industrial applications'. 'Technology' would be its core engine-driver for the future. NAL is also best known for its main sophisticated aerospace R\&D testing facilities which are not only unique for this country but also comparable to similar facilities elsewhere in the world. CSIR-NAL provides access to a large number of Aerospace bibliographic databases to its scientists, engineers and technologists through a consortia tie-up with CSA Illumina (formerly Cambridge Science Abstracts), which is a provider of online databases based in Ann Arbor, Michigan. Most importantly, The CSA High Technology Research Database is a major abstracting and indexing datasbase and category in the CSA Illumina database structure. It is considered to be the online equivalent of International Aerospace Abstracts (IAA) and Scientific and Technical Aerospace Reports (STAR from 1962 to 1993). The Aerospace and High Technology Database is a bibliographic database covering the space sciences as well as aeronautics and astronautics. This database also provides access to complimentary disciplines, such as electronics, chemistry, physics, geosciences, and communications. Every CSIR-NAL scientist has access to this aerospace database right at his desktop.

\section{Objectives of the Study}

To determine whether there is any association of 'Demographic Variables by the Frequency of 'Use of Core Aerospace Engineering e-Databases' amongst the aerospace scientists and engineers of Bangalore.

To determine whether the percentage of preference for the demographic variables, viz., (a) Category wise distribution of the respondents [Aerospace Scientist / Aerospace Engineer], (b) Occupation profile, (c) Gender, (d) Age groups, (e) Qualification and (f) Specialization by the Frequency of Use of Core Aerospace Engineering e-Databases' are approximately the same.

\section{Null Hypotheses}


There is no association between the 6 demographic variables, namely, (a) Category wise distribution of the respondents [Aerospace Scientist / Aerospace Engineer], (b) Occupation profile, (c) Gender, (d) Age groups, (e) Qualification and (f) Specialization of the respondents by the 'Frequency of Use of Core Aerospace Engineering e-Databases' by the Aerospace Scientists and Engineers.

\section{Materials and Methods}

The present study is restricted to the selected 16 prominent aerospace organizations in Bangalore. A total number of 650 survey questionnaires were distributed amongst the aerospace scientists and engineers belonging to these 16 aerospace organizations. A total number of 612 questionnaires were received back finally $583(89.7 \%)$ were selected for the study which were found suitable for the study.

A survey questionnaire has been used to conduct this research study. The total population size of this research study is restricted to the 1220 aerospace scientists and engineers in Bangalore. The distribution of Source Data is indicated in Table 1. Random sampling technique has been used for selection of the sample size.

Table-1: Distribution of Source Data (Sample Size)

\begin{tabular}{|c|c|c|c|c|}
\hline SI.No. & Organizations & $\begin{array}{c}\text { No. of Questionnaires } \\
\text { distributed }\end{array}$ & $\begin{array}{l}\text { No. of Questionnaires } \\
\text { received }\end{array}$ & $\begin{array}{l}\text { No. of usable questionnaires } \\
\text { usable }\end{array}$ \\
\hline 1. & $\mathrm{ADA}$ & 67 & 63 & 58 \\
\hline 2. & AFTC & 19 & 16 & 15 \\
\hline 3. & $\mathrm{ADE}$ & 14 & 12 & 12 \\
\hline 4. & ASTE & 33 & 30 & 29 \\
\hline 5. & CABS & 16 & 15 & 14 \\
\hline 6. & CEMILAC & 33 & 30 & 29 \\
\hline 7. & C-MMACS & 8 & 6 & 6 \\
\hline 8. & DARE & 11 & 9 & 9 \\
\hline 9. & LRDE & 5 & 3 & 2 \\
\hline 10. & GTRE & 24 & 22 & 21 \\
\hline 11. & HAL & 144 & 140 & 134 \\
\hline 12. & IAM & 40 & 36 & 33 \\
\hline 13. & ISRO-ISTRAC & 25 & 24 & 22 \\
\hline 14. & IISc & 38 & 37 & 34 \\
\hline 15. & JNCASR & 5 & 3 & 1 \\
\hline 16. & NAL & 168 & 166 & 164 \\
\hline Total & & 650 & 612 & $583(89.7 \%)$ \\
\hline
\end{tabular}

Geographical Boundary of the Study (16 Prominent Aerospace Organizations of Bangalore, INDIA).

Key: $\mathrm{ADA}=$ Aeronautical Development Agency, AFTC $=$ Air Force Technical College, $\mathrm{ADE}=$ Aeronautical Development Establishment, ASTE=Aircraft Systems Testing Establishment, $\mathrm{CABS}=$ Centre for Airborne Systems, CEMILAC $=$ Centre for Military Airworthiness and Certification, $\mathrm{C}$-MMACS $=$ Centre for Mathematical Modeling and Computer Simulation, DARE=Defense Avionics Research Establishment, LRDE=Electronics and Radar Development Establishment, GTRE $=$ Gas Turbine Research Establishment, $\mathrm{HAL}=$ Hindustan Aeronautics
Limited, IAM=Institute of Aerospace Medicine, ISRO-ISTRAC $=$ Indian Space Research Organization, $\mathrm{IISc}=$ Indian Institute of Science, JNCASR=Jawaharlal Nehru Centre for Advanced Scientific Research, $\mathrm{NAL}=$ National Aerospace Laboratories.

The analysis of 'Association of Demographic Variables versus Frequency of Use of Core Aerospace Engineering e-Databases' amongst the aerospace scientists and engineers of the selected 16 aerospace organizations of Bangalore is shown in Table 2. 
Table-2: Association of Demographic Variables versus Frequency of Use of Core Aerospace Engineering e-Databases

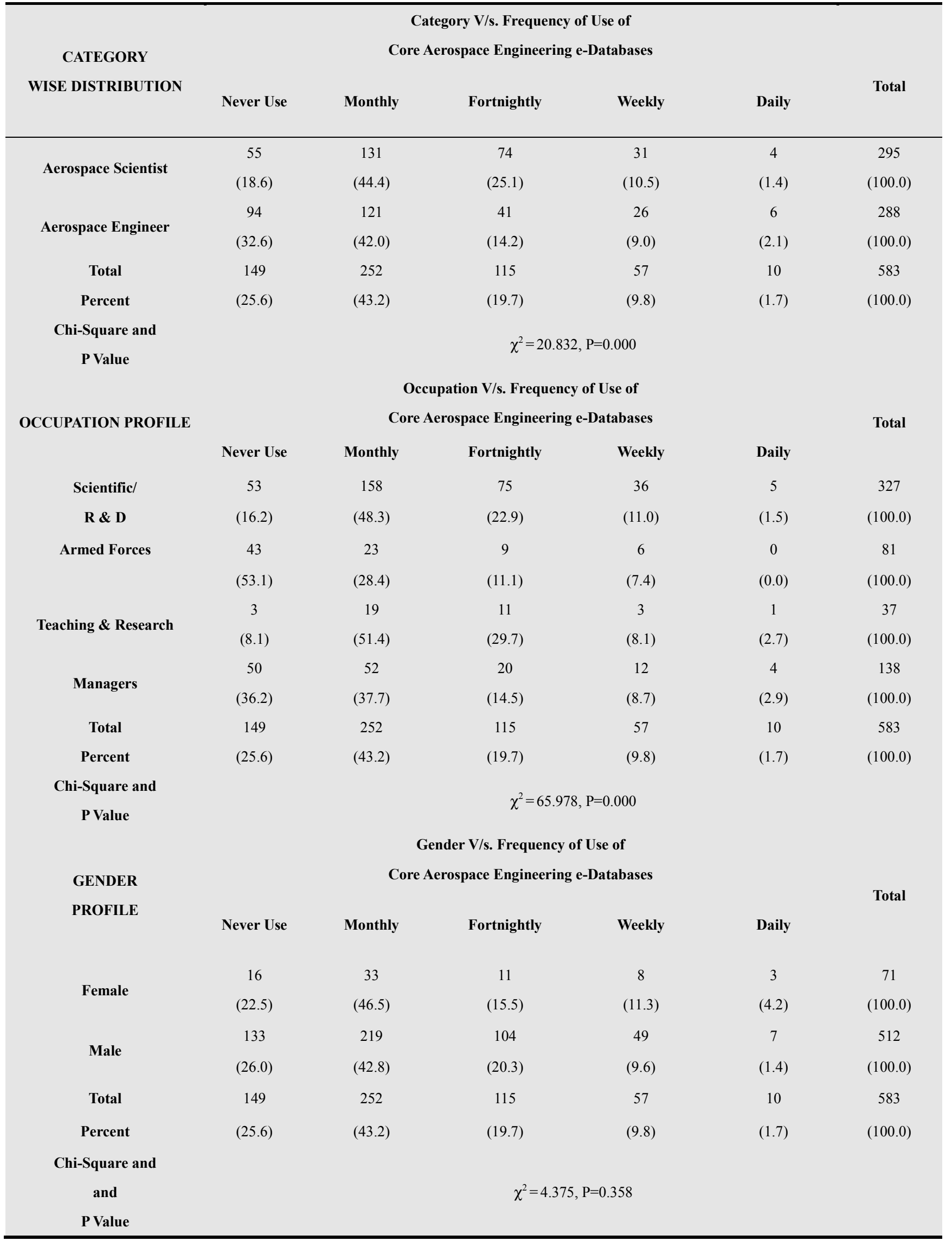




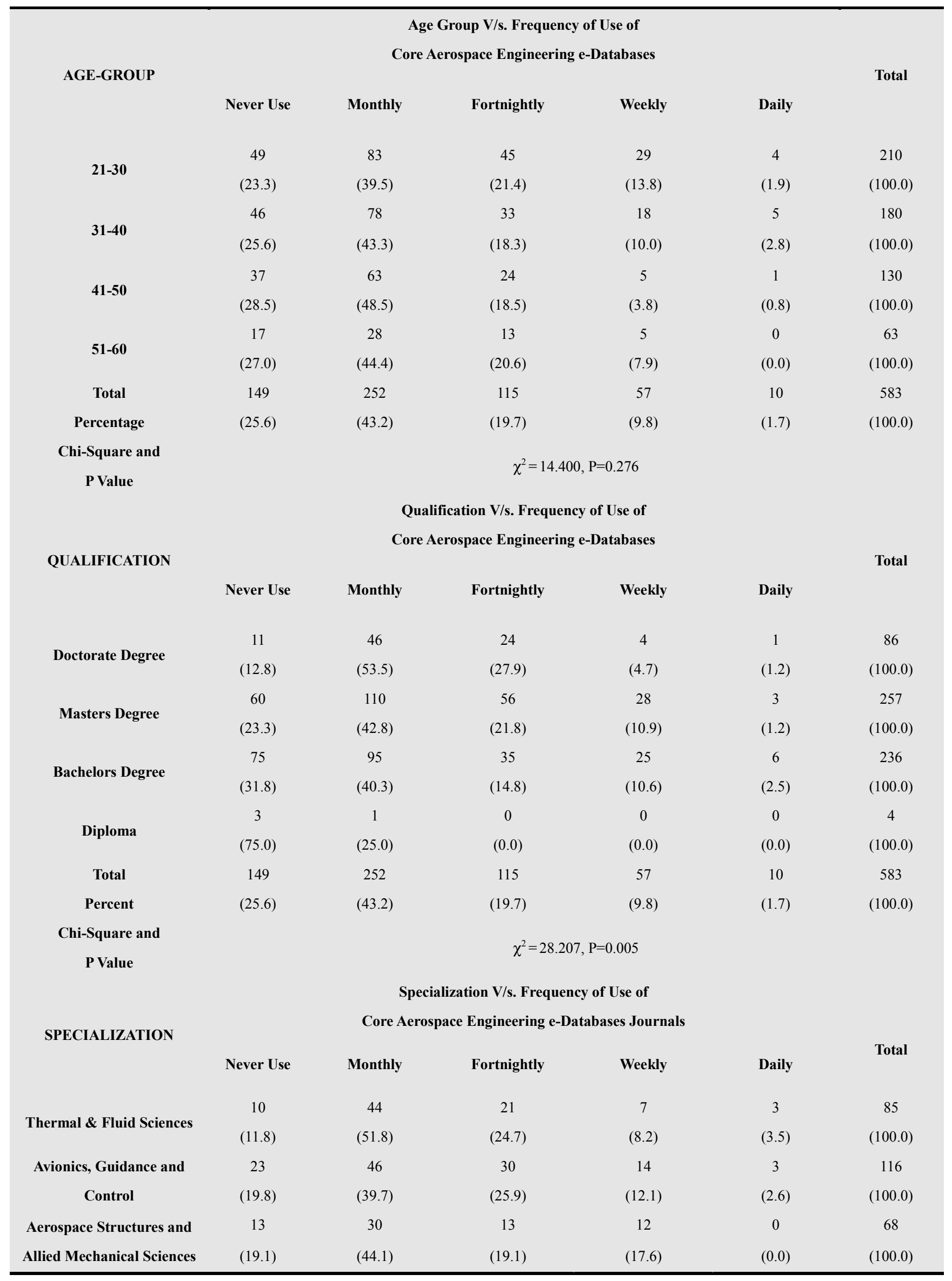




\begin{tabular}{|c|c|c|c|c|c|c|}
\hline Materials and Metallurgy & $\begin{array}{c}6 \\
(20.7)\end{array}$ & $\begin{array}{c}16 \\
(55.2)\end{array}$ & $\begin{array}{c}7 \\
(24.1)\end{array}$ & $\begin{array}{c}0 \\
(0.0)\end{array}$ & $\begin{array}{c}0 \\
(0.0)\end{array}$ & $\begin{array}{c}29 \\
(100.0)\end{array}$ \\
\hline $\begin{array}{l}\text { Flight Operations and } \\
\text { other Allied Disciplines }\end{array}$ & $\begin{array}{c}20 \\
(42.6)\end{array}$ & $\begin{array}{c}19 \\
(40.4)\end{array}$ & $\begin{array}{c}5 \\
(10.6)\end{array}$ & $\begin{array}{c}3 \\
(6.4)\end{array}$ & $\begin{array}{c}0 \\
(0.0)\end{array}$ & $\begin{array}{c}47 \\
(100.0)\end{array}$ \\
\hline General Engineering and & 77 & 97 & 39 & 21 & 4 & 238 \\
\hline Support Sciences & $(32.4)$ & $(40.8)$ & $(16.4)$ & $(8.8)$ & (1.7) & $(100.0)$ \\
\hline Total & 149 & 252 & 115 & 57 & 10 & 583 \\
\hline Percent & $(25.6)$ & $(43.2)$ & $(19.7)$ & $(9.8)$ & (1.7) & $(100.0)$ \\
\hline $\begin{array}{c}\text { Chi - Square and } \\
\text { P Value }\end{array}$ & \multicolumn{6}{|c|}{$\chi^{2}=42.228, \mathrm{P}=0.003$} \\
\hline
\end{tabular}

Key1: Frequency of Usage of Core Aerospace Engineering e-Databases: (1) Aerospace databases, (2) AIAA meeting papers, (3) IEEE Explore, (4) NASA Technical Reports Server (NTRS), (5) NTIS (CSA), (6) Aerospace - Aerospace and High Technology Database through CSA (Cambridge Science Abstracts), (7) Inside Science, (8) Thomas Register, (9) SAE International (aerospace.sae.org), (10) Compendex, (11) INSPEC, (12) Aerospace Defense Industry Data Finder.

Key2: Figures in Brackets indicate Percentages

\section{Results and Discussion}

The $\chi 2$ test indicates that the demographic variable, viz., Category Wise Distribution of the Respondents, namely, Aerospace Scientist / Aerospace Engineer, $(\chi 2=20.832$, $\mathrm{P}$ Value $=0.000)$, Occupation $(\chi 2=65.978, \mathrm{P}$ Value $=0.000)$, Qualification $(\chi 2=28.207, \quad \mathrm{P}$ Value $=0.005)$, and Specialization $(\chi 2=42.228, \quad \mathrm{P}$ Value $=0.003)$, by the 'Frequency of Use of Core Aerospace Engineering e-Databases' have significant association.

The $\chi 2$ tests for the remaining demographic variables, namely, Gender and Age-Group by the 'Frequency of Use of Core Aerospace Engineering e-Databases' have no significant association.

\section{Conclusion}

The main conclusions that the authors would like to infer in this paper are:

- The $\chi 2$ test indicates that the demographic variable, viz., Category Wise Distribution of the Respondents, namely, Aerospace Scientist / Engineer $(\chi 2=20.832$, $\mathrm{P}$ Value $=0.000)$, Occupation $(\chi 2=65.978, \mathrm{P}$ Value $=$ $0.000)$, Qualification $(\chi 2=28.207$, P Value $=0.005)$, and Specialization $(\chi 2=42.228$, $P$ Value $=0.003)$, by the 'Frequency of Use of Core Aerospace Engineering e-Databases' have significant association.

- This implies that the percentage of preference for the above mentioned demographic variables are not approximately the same [Not Uniformly distributed].

- The $\chi^{2}$ tests for the remaining demographic variables, namely, Gender and Age-Group by the 'Frequency of Use of Core Aerospace Engineering e-Databases' have no significant association.

- This implies that percentages of preference for these demographic variables are approximately the same [Uniformly distributed].

\section{Acknowledgments}

The authors would like to express their gratitude and thankfulness to Mr. Shyam Chetty, Director, CSIR-NAL for all the support and encouragement. The authors are very grateful to Head, KTMD for supporting this research work.

\section{References}

[1] Kanungo, N.T. (2007), 'Use of Internet in the Scholarly Communication of Social Scientists: A Case Study of IGNOU, 54(2007), 7-18.

[2] Maharana, B., and Nayak, K., (2006), 'Scholarly Use of Web Resources in LIS Research: A Citation Analysis, Library Review, 55(9), 598-607.

[3] Li L, (2006), 'Leveraging Quality Web-Based Library User Services in the Digital Age', Library Management, 27(6/7), 390-400.

[4] Nikam K and Kumar D (2013), 'Evaluating the Effective Use of Electronic Journals by the Academic: A Study', DESIDOC Journal of Library and Information Technology, 33(2), 125-130.

[5] Lawrence B, (1990). Database Publishers - Challenges for the Future, Information Services and Use, 10(5).

[6] Blado W R and Cotter G A (1992). An international aerospace information system: a cooperative opportunity, Online Information Review, 16(6), 359-368.

[7] O'Flaherty J J (1997). EURILIA - European Initiative in Library and Information in Aerospace, Interlending \& Document Supply, 25(4), 157-165.

[8] Jeong M J, Cho K W and Kim K Y (2007). e-AIRS: Aerospace Integrated Research Systems, International Symposium on Collaborative Technologies and Systems, $\mathrm{http} / / /$ ieeexplore.ieee.org/xpls/abs all.jsp?arnumber $=462172$ 
$6 \& \operatorname{tag}=1$

[9] Pinelli et al. (1991, 2002). An analysis of the technical communications practices reported by Israeli and US aerospace engineers and scientists, Professional Communication Conference, 1991. IPCC'91. Proceedings. The Engineered Communication, International, 2, 420-435.

[10] Sripada S M, (2002). Information Management Challenges from the Aerospace Industry, Proc. 28th VLDB Conference, Hong Kong, China.

[11] Hatua S R and Madalli D P (2011). AERIS: An Integrated Domain Information System for Aerospace Science and Technology, Program: Electronic Library and Information Systems, 45(2), 199-212.

[12] Riahinia, N. and Zandian, F (2007), 'Evaluation of Information Providers and Popular Search Engines on the Base of Postgraduate Students' perspectives. The Electronic Library, 26(4), 2008, 596-604, CEmerald Group Publishing Limited, DOI 10.1108/02640470810893819.

[13] Sharma, C., Singh, L., and Sharma, R (2011), 'Usage and acceptability of e-resources in National Dairy Research Institute (NDRI) and National Bureau of Animal Genetic Resources (NBAGR), India, The Electronic Library, 29(6), 803-816.
[14] Kamba, M.A. (2011), 'Implication of ICT's in Libraries of Higher Education Institutes: A Panacea Catapulting Library Development in Africa' DESIDOC Journal of Library and Information Technology, 31(1), 65-71.

[15] Bonzi, S. Senior faculty perception of research productivity. In Proceedings of the ASIS, Annual Meeting, Knowledge Industry Publication Inc., Washington DC, 1992.

[16] Bankole O.M., (2013), 'The use of internet services and resources by scientists at Olabisi Onabanjo University, Ago Iwoye, Nigeria, Electronic Library and Information Systems, 47(1), 15-33.

[17] Maharana, B., and Champeswar, M. (2007), 'A Survey of Digital Information Literacy of Faculty of Sambalpur University, Library Philosophy and Practice, Paper 144, http://digitalcommons.unl.edu/libphilprac/144

[18] (http://www.lib.ied.edu/hk/is/tutorial/module2/e resources/2 1/2_1_content.htm).

[19] (http://en.wikipedia.org/wiki/Online_database)

[20] (www.dundeecity.gov.uk/library/termsltow).

[21] http://en.wikipedia.org/wiki/Online_database, http://www.wisegeek.org/what-is-demography.htm, www.nal.res.in, www.icast.org.in 